\title{
THE MECHANISM OF FRICTION BETWEEN SURFACES WITH REGULAR MICRO GROOVES UNDER BOUNDARY LUBRICATION
}

\author{
Mykhaylo Pashechko', Myroslav Kindrachuk², Oleksandr Radionenko³ \\ Department of Fundamentals of Technology, Lublin University of Technology, Nadbystrzycka 38, 20-618 \\ Lublin, Poland, e-mail: mpashechko@hotmail.com \\ 2 Engineering Department, National Aviation University, Kyiv, Ukraine, e-mail: nau12@ukr.net \\ 3 Department Mechanical and Engineering, Pryazovskyi State Technical University, Mariupol, Ukraine
}

Received: 2016.06.28

Accepted: 2016.10.08

Published: 2016.12.01

\begin{abstract}
The results of researches related to the influence of partially regular microrelief parameters on the adhesion component of the friction factor under boundary lubrication have been given. A special ring-on tape test rig is proposed in order to avoid errors during running-in process. Special technique is used to form sinusoidal microgrooves what helped to create a partially regular microrelief on the surface with controlled contour and nominal contact areas. Fatigue and deformation components of wear process are considered. We proved that microtexturing with proposed parameters decreases the adhesion component of friction and reduces the probability of microwelding. It has been shown that under boundary friction micro grooves are effective on precision surfaces with low roughness when lack of film and probability of seizure appear.
\end{abstract}

Keywords: friction, microrelief, surface, lubrication, micro grooves.

\section{INTRODUCTION}

According to Molecular Mechanics Theory of Friction the total friction force under boundary lubrication can be resolved into an adhesion component and a deformation component. The measurement of these components can be done with some difficulties. This paper has investigated the adhesion and deformation components of friction under boundary lubrication of surfaces with regular micro grooves.

There are many technological methods to improve the tribological characteristics of sliding friction pairs by microtexturing techniques [1-4, $6,7,11]$. One of these methods is the formation of sinusoidal micro grooves regularly spaced on friction surfaces that are called "surfaces with a partially regular microrelief” according to GOST 24773-81 [12]. The grooves are formed by means of surface plastic deformation performed by the spherical indenters (Fig. 1). The depth of these grooves can be taken from 5 to $50 \mu \mathrm{m}$.
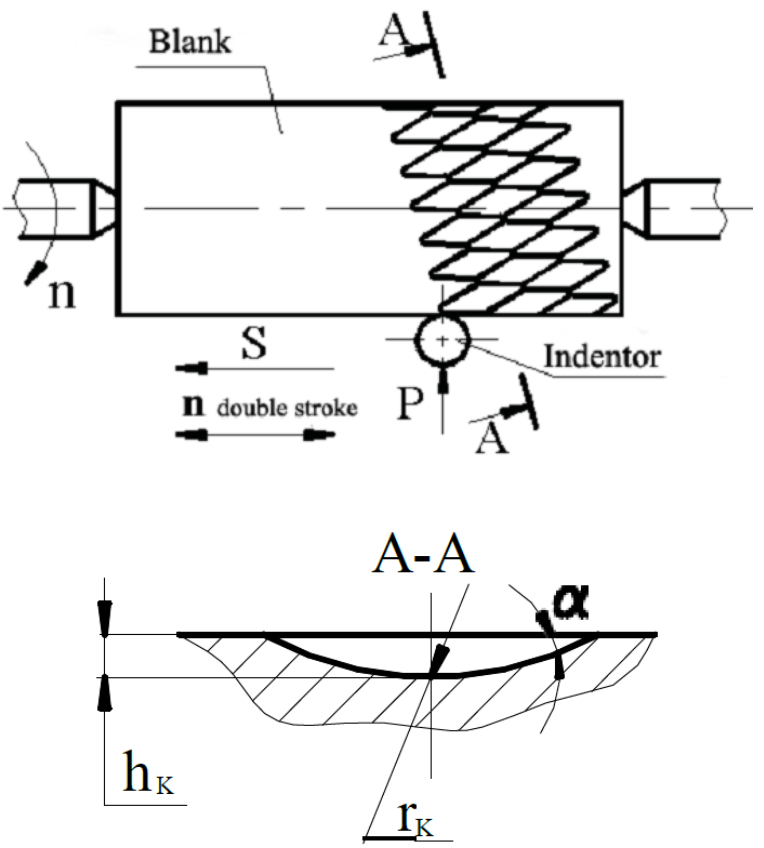

Fig. 1. Model of a partially regular microrelief formation by surface plastic deformation 
To research the influence of surfaces with a partially regular microrelief on the tribological characteristics of samples, it is necessary to eliminate the influence of shape errors as well as the influence of friction surface position errors. It is not possible to eliminate the influence of these errors when applying the tribometer used in mechanical engineering. In order to eliminate the mentioned errors, macro running-in of the samples to equalize the nominal contact area and contour contact area is required. During this process micro running-in takes place and uniform roughness is formed [5].

\section{METHODS}

To conduct tribological researches without using macro running-in, the new tribometer has been developed on the basis of friction between shaft and metal tape $[8,9]$. The metal tape can be used as a mating sample and due to its small thickness $\mathrm{mm}$, it is flexible, which allows it to locate itself on the sample without shape errors and surface position errors. Thus the nominal contact area and contour contact area are equalized. The tribometer is equipped with an air damper to reduce self- oscillations and with an inductive friction torque transmitter (Fig. 2). The drive of a tribometer has the ability to provide stepless speed control of the sample. Different loading can be obtained by means of two tension springs and application of mating samples of different lengths. This tribometer allows one to perform testing at pressure up to $2 \mathrm{MPa}$ on a sample and at loading to $470 \mathrm{~N}$. Due to small thickness of the tape it is possible to control the temperature in the friction area with high precision. This is achieved

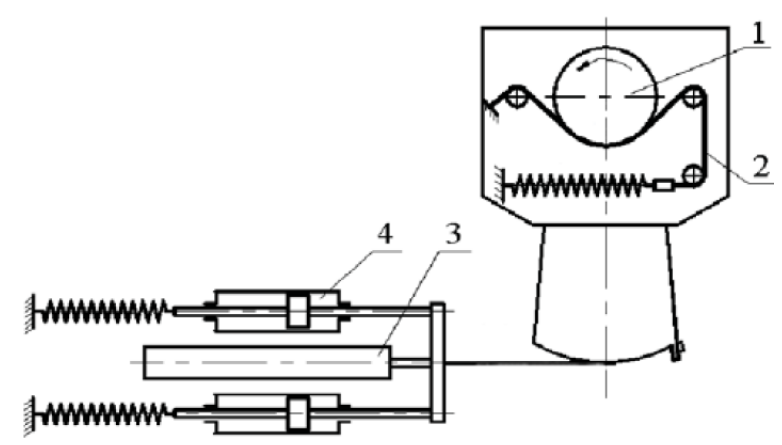

Fig. 2. Diagram of a tribometer: 1 - sample; 2 - steel tape as a mating sample; 3 -friction torque transmitter; 4 - air dampers by soldering the chromel-copel thermocouple of $\varnothing 0.2 \mathrm{~mm}$ directly to tape of a mating sample over the friction area. The tribometer and its instrumentation allow one to control lubrication modes (boundary lubrication, mixed lubrication, liquid lubrication) according to the electrical resistance of lubricant film. While studying surfaces with a partially regular microrelief friction torque is monitored and friction factor is calculated by a formula obtained on the basis of the Euler equation derived for the case of wrapping the shaft with a flexible cable.

The purpose of the research of surfaces with a partially regular microrelief is to study the influence of micro grooves on adhesion and deformation components of the friction factor, and identification of the lubricant removal mechanism from the micro grooves.

All the studies were conducted with oil 'Industrial 20' and steel C45 of $30 \ldots 32$ HRC. Micro grooves of different depth $h_{K}$, the radius of the bottom $r_{K}$ and the relative area $F_{K}$ are formed parallel to a cylinder element on the samples of $30 \mathrm{~mm}$ diameter by means of plastic deformation.

The adhesion component was studied using the method of exclusion of the deformation component of friction, for which the roughness of samples and the roughness of mating samples were taken as $R_{z}=0.08 \ldots 0.1 \mathrm{~mm}$. The surface of the sample was fed with a strictly dosed small drop of oil on, carefully distributed over the entire surface. The measurement of friction torque is performed with $3 \ldots 5$ friction cycles at maximum friction. From the start of friction a small number of cycles did not change the initial roughness, and provided self-location of a mating sample (tape) on the sample and a reliable contact of the friction surfaces. After $3 \ldots 5$ cycles there was a decrease of friction force due to the beginning of formation of the uniform roughness and improvement of lubrication conditions. All experiments related to the adhesion component were performed under boundary lubrication at sliding velocity of $3.14 \cdot 10^{-2} \mathrm{~m} / \mathrm{s}$. The temperature was kept constant at $(33 \pm 2)^{\circ} \mathrm{C}$.

It was necessary to research surfaces with different areas of micro grooves FK and consequently surfaces with different contour areas of contact. The preliminary experiment was carried out to identify the influence of contour pressure $\mathrm{pC}$ on the friction factor for samples without micro pits. The experiment confirmed the total independence of the friction factor $f$ after micro 
running-in and the adhesion component of the friction factor $\mathrm{f}_{\mathrm{a}}$ from contour pressure $\mathrm{pC}$ in the range to $2 \mathrm{MPa}$ for both surfaces without micro grooves and surfaces with micro grooves.During the studies, the possible location of a mating sample along the chord (effect of a chord) above a micro groove has been verified. In this case the thin steel tape is used as a mating sample. Besides, the influence of the above mentioned effect on the readings of the tribometer has been determined. The test results have shown that "the effect of a chord" does not appear.

In this experiment the friction factor fa depends on the relative area of micro grooves $\mathrm{F}_{\mathrm{K}}$ due to lubrication mechanisms only, in other words, due to the ability of friction surfaces to absorb lubricant from micro grooves and to form reliable boundary lubrication.

The depth of micro grooves $h_{K}$ and their radius $r_{K}$ affect $f_{a}$ value and consequently the ability to absorb lubricant from micro grooves. When the depth of micro grooves decreases and their radius increases the absorption of lubricant from micro grooves improves and the adhesion component of the friction factor decreases. To determine the role of deformation component, running-in of surfaces with micro grooves has been studied.

For this purpose, the duration of micro running-in of the samples with micro grooves and mating samples has been studied. During research a flexible steel tape with surface roughness ranged from 5 to $7 \mu \mathrm{m}(\mathrm{Ra} \approx 0.8 \mu \mathrm{m})$ was used as a mating sample. The roughness of the tape was provided by means of grit paper, and the direction to the roughness traces was made perpendicular to the tape axis.

Research was conducted with the help of the tribometer (Fig. 2) using samples from steel C45 of hardness $28 \ldots 32 \mathrm{HRC}$ and mating samples in the form steel tape of grade C80W2 with thickness $0.06 \mathrm{~mm}$.

Micro grooves on samples were formed as a result of pressing with a spherical indenter with radius $r=1.5 \mathrm{~mm}$. Micro grooves were located parallel to a cylinder element. Cold laps and metal swellings on the edges of micro pits were carefully removed in order to provide the minimum obstruction of the edges of micro grooves. Carrying surface roughness was ranged from $\mathrm{R}_{\mathrm{z}}=0.8$ to $1.0 \mu \mathrm{m}(\mathrm{Ra} \approx 0.15 \mu \mathrm{m})$. The researches were conducted in the boundary lubrication mode using oil 'Industrial $20^{\text {' }}$ at the sliding velocity $\mathrm{V}=$ $3.14 \cdot 10^{-2} \mathrm{~m} / \mathrm{s}$. In all experiments contour pressure was calculated for the surfaces excluding the area of micro grooves and was equal to $\mathrm{p}_{0}=0.61 \mathrm{MPa}$. Duration of micro running-in was determined depending upon the time taken before the friction factor was stabilized. During the process of micro running-in the excess of lubricant was provided, as evidenced, by its appearance in the inlet area of friction.

Boundary lubrication mode was controlled by the electric resistance in the contact area and by the oscilloscope displays.

\section{RESULTS}

The experiment has confirmed the dependence of micro running-in duration on the relative area of micro grooves $F_{k}$, which allows making conclusion about an engagement of micro asperity projections with the edges of micro grooves [10].

The rate of micro running-in is affected by the loading cyclicity of micro asperity projections, which causes their fatigue failure. The greater the relative area of micro grooves $F_{k}$ at the constant width $b_{k}$ is, the faster micro running-in is finished. Under sliding friction in the boundary lubrication mode the loading cyclicity of micro asperity projections can lead to more extensive wear of a friction surface mated with the surface where micro grooves are formed. But this is compensated by the decrease of wear which occurs due to the formation and destruction of adhesive welding bridges, and the most important thing is that the probability of seizure is eliminated.

Fatigue wear can be considered a growth of a wear value under normal friction in the mode of boundary or mixed lubrication when the relative area of micro grooves $F_{k}$ increases and its value exceeds the optimum value $\mathrm{F}_{\mathrm{k}}=25 \ldots 45 \%$.

The value of the deformation component of friction force should increase in case of micro seizure, because the break of adhesive welding bridges is accompanied by the removal of metal micro particles welded to the mating surface projections from the friction surface. This leads to the formation of higher projections with high hardness, which engage with the edges of micro grooves and significantly deform them.

Decrease in the deformation component of friction force reduces the energy cost for friction during the steady state mode of friction as well as improves the smoothness of movement. The latter is indicated by decrease in the variations 
of friction force when tape surface roughness is reduced from $\mathrm{R}_{\mathrm{z}}=5 \ldots 7 \mu \mathrm{m}$ to $\mathrm{R}_{\mathrm{z}}=2 \ldots 3 \mu \mathrm{m}$. At the same time, in order to accelerate the process of running-in it is necessary to increase the deformation component of friction.

The necessary depth of micro grooves should be made in order to ensure good running-in of the friction surfaces, which results in light surface wear and reduction of groove depth. Profile of grooves is also changed, so one of the edges gets more rounded. Upon completion of runningin the grooves with less depth and rounded edges of micro grooves provide a reduction of adhesion and deformation components of friction and decrease wear on the friction surfaces in comparison with the period of running-in.

\section{CONCLUSIONS}

The formation of micro grooves of 3-20 $\mu \mathrm{m}$ on the friction surface reduces the adhesion component of friction force under boundary lubrication, if the friction surfaces do not have micro cavities to reserve lubricant. This friction pair ought to have minimum clearance, high accuracy in shape (round surface, longitudinal section profile) and with minimum surface roughness less than $\mathrm{R}_{\mathrm{z}}=0.8 \ldots 1.0 \mu \mathrm{m}$ ).

Micro grooves increase the deformation component of friction force under boundary lubrication, especially when surface roughness on the mating friction surface.

Thus, the formation of micro grooves on friction surfaces under boundary lubrication is highly applicable for precision friction units, for example, in the boxes of theodolites, in the friction units of telescopes and other precision devices.

The effect of micro grooves under boundary lubrication appears in cases when the friction surfaces are unable to provide normal modes of friction and lubrication. If a friction pair is run in and operates without deviations, it will be inappropriate to form micro grooves on contacting surfaces in order to improve the mechanism of lubrication and increase their wear resistance, except cases when structural errors were made during the process of a new friction pair design.

\section{REFERENCES}

1. Sista B. and Vemaganti K. Estimation of statistical parameters of rough surfaces suitable fordeveloping micro-asperity friction models. Wear, 316(12), 2014, 6-18.

2. Blatter A., Maillat M., Pimenov S.M., Shafeev G.A., Simakin A.V. and Loubnin E.N. Lubricated sliding performance of laser-patterned sapphire. Wear, 232(2), 1999, 226-230.

3. Adatepe H., Biyıkloglu A. and Sofuoglu H. An investigation of tribological behaviors of dynamically loaded non-grooved and micro-grooved journal bearings. Tribology International, 58, 2013, 12-19.

4. Ibatan T., Uddin M.S. and Chowdhury M.A.K. Recent development on surface texturing in enhancing tribological performance of bearing sliders. Surface and Coatings Technology, 272, 2015, 102-120.

5. Okamoto M., Jibiki T., Ito S. and Motoda T. Role of cross-grooved type texturing in acceleration of initial running-in under lubricated fretting. Tribology International, 100, 2016, 126-131.

6. Pashechko M. and Barszcz M. Eutectic alloy matrix, comprises manganese, carbon, boron, silicon, nickel, chromium, copper and iron. Patent, PL403566-A1, 2016.

7. Pashechko M., Dziedzic K. and Barszcz M. Study of the structure properties of wear-resistant eutectic Fe-Mn-C-B-Si-Ni-Cr coatings. Powder Metallurgy and Metal Ceramics, 52(7-8), 2013, 469-476.

8. Radionenko A. Lubricant mechanism of surfaces with a partially regular microrelief. Kyiv: Press of National Aviation University. Problems of Tribology, 4, 2005, 203-206.

9. Radionenko A. The tribometer to study the influence of surface quality on the condition of lubricant film. Mashinovedeniye, 1987, 93-97.

10. Radionenko A. and Kindrachuk M. Friction model and technological support of surfaces with a partially regular microrelief. Kyiv, Press of National Aviation University. Problems of Tribology, 1, 2005, 59-68.

11. Saeidi F., Meylan B., Hoffmann P. and Wasmer K. Effect of surface texturing on cast iron reciprocating against steel under starved lubrication conditions: A parametric study. Wear, 348-349, 2016, 17-26.

12. Schneider Yu. Operational properties of details with regular microrelief. Leningrad: Mashinostroyeniye, 1982, 248. 